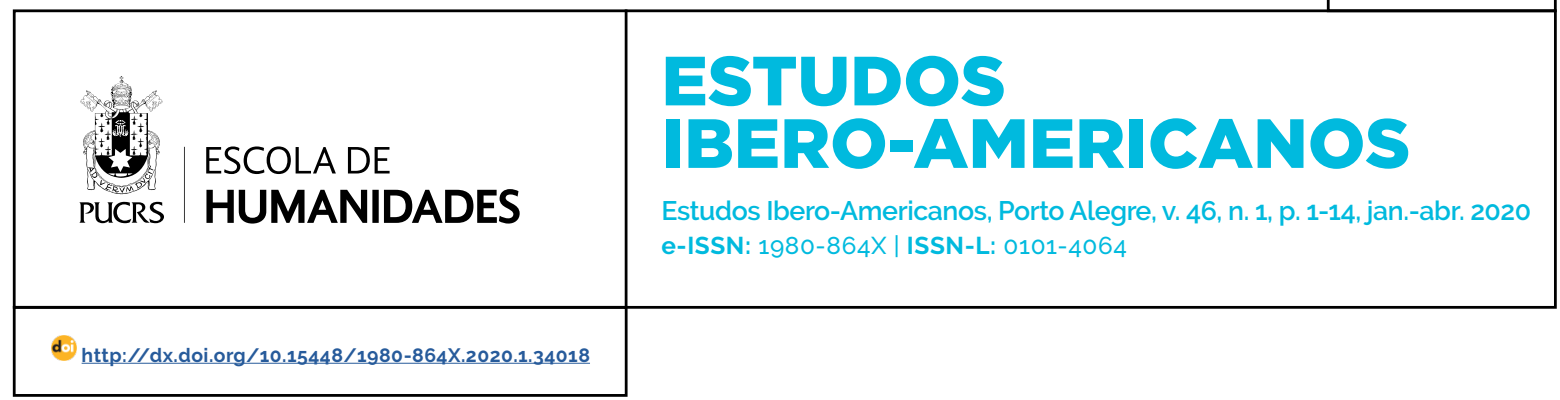

SEÇÃO: DOSSIÊ

\title{
Pobreza e vulnerabilidade: uma história social dos desastres de 1974 na Bacia do Rio Tubarão (SC-Brasil)
}

\author{
Poverty and vulnerability: a social history of disasters in 1974 in the Tubarão River Basin \\ (SC-Brazil) \\ Pobreza y vulnerabilidad: una historia social de los desastres de 1974 en la Cuenca del \\ Río Tubarão (SC-Brasil)
}

\section{Alfredo Ricardo Silva Lopes $^{1}$ orcid.org/0000-0001-5588-8279 alfredo.lopes@ufms.br}

Recebido em: 7 mai. 2019. Aprovado em: 26 set. 2019 Publicado em: 28 abr. 2020.
Resumo: O presente artigo analisa a enchente e os deslizamentos de massa ocorridos na Bacia Hidrográfica do Rio Tubarão em 1974, no intuito de analisar as estratégias de interação com o ambiente e as medidas tomadas pelo Estado Brasileiro para evitar o desmantelamento da cidade. Nesse contexto, a condição de afetado pelo desastre foi noticiada na condição de vítima ou vilão pelos periódicos nacionais e estaduais, variando segundo os interesses das classes dirigentes com o trabalho dos flagelados na recuperação da cidade. O desastre socioambiental é entendido neste trabalho como um acontecimento totalizante. que exprime as lógicas de dominação impostas ao ambiente e aos indivíduos. Desta forma, percebeu-se que na Bacia do Rio Tubarão a pobreza é a condição mais significativa para produção da vulnerabilidade a desastres socioambientais. Palavras chave: História social. Desastres socioambientais. Bacia Hidrográfica do Rio Tubarão.

Abstract: This article analyzes the flood and mass landslides in the Tubarão River Basin in 1974. The objective is to evaluate the measures taken by the Brazilian government in order to avoid the dismantling of the city. In this context, the condition "affected by the disaster" was reported by national and regional newspapers as a victim or villain, which varied according to the interests of ruling classes in the work of affected people. Disaster is understood in this work as a totalizing event, which expresses the logics of domination imposed on the environment and to the individuals. Thus, it was realized that at the Tubarão River Basin, poverty is the most significant condition to the production of vulnerability to social and environmental disasters.

Keywords: Social history. Socioenvironmental disasters. Tubarão River Basin.

Resumen: El presente artículo analiza la inundación y los deslizamientos de masa ocurridos en la Cuenca Hidrográfica del Río Tubarão en 1974, con el propósito de las estrategias de interacción con el ambiente y las medidas tomadas por el Estado Brasileño para evitar el desmantelamiento de la ciudad. En ese contexto, la condición de afectado por el desastre fue notificada en la condición de víctima o villano por los periódicos nacionales y estatales, variando según los intereses de las clases dirigentes en el trabajo de los flagelados. El desastre es entendido en este trabajo como un acontecimiento totalizante, que expresa las lógicas de dominación impuestas al ambiente y a los individuos. Por lo tanto, se dio cuenta de que en la cuenca del río Tubarão la pobreza es la condición más importante para producir vulnerabilidad a los desastres sociales y ambientales. Palabras clave: Historia social. Desastres socioambientales. Cuenca Hidrográfica del Río Tubarão. 


\section{Introdução}

Há aproximadamente 10 mil anos no Holoceno, com o fim da última glaciação, foram estabelecidas as condições para o pleno desenvolvimento da vida humana na terra. Nesse periodo, com a diminuição da variabilidade climática, um padrão de normalidade climática começou a balizar o significado dos desastres que chega até os dias atuais. No começo do século XXI foi possivel perceber a força das transformações impostas pela humanidade ao planeta.

Nos últimos duzentos anos, a capacidade humana de apropriação dos assim denominados recursos naturais cresceu exponencialmente e, por isso, as dinâmicas biogeofísicas do planeta também foram alteradas, o que corrobora com a teoria de que os seres humanos estariam produzindo uma nova era geológica, o Antropoceno (CRUTZEN; STEFFEN, 2003). A possibilidade da conversão energética alcançada na Revolução Industrial ofereceu aos seres humanos uma possibilidade inalcançada até hoje por nenhuma outra espécie, a de produzir meios de transformar as dinâmicas naturais do planeta (CRUTZEN; STEFFEN, 2003).

Com as transformações produzidas em escala global e local, o impacto dos desastres socioambientais passou a ser cada vez mais significativo em todas as regiões do planeta. Assim, os habitantes do que se convencionou chamar de Estado de Santa Catarina no Sul do Brasil vêm experienciado uma grande variedade de intempéries climáticas, em especial as enchentes, em função do estabelecimento dos núcleos populacionais próximos aos rios.

Os ocupantes da Bacia Hidrográfica do Rio Tubarão, desde os primeiros povos indígenas até os eurodescendentes, vêm convivendo e lidando com tais enchentes rotineiras. Devido à chuva fraca que começou no dia 22 de março de 1974, quando a chuva se intensificou no domingo de 24 de março de 1974 o solo já não tinha mais condições de absorver a água. As massas de ar úmido que vinham do oceano Atlântico se chocavam com as escarpas da Serra Geral produzindo enchentes bruscas da Bacia Hidrográfica do Rio Tubarão, que dá nome a cidade, até a divisa com o Rio Grande do Sul na Bacia Hidrográfica do Rio Mampituba. Vários deslizamentos correram pela planície aluviam destruindo casas e plantações. A BR101 ficou intransitável por duas semanas, para evitar com que as pessoas deixassem suas casas em Tubarão e Araranguá.

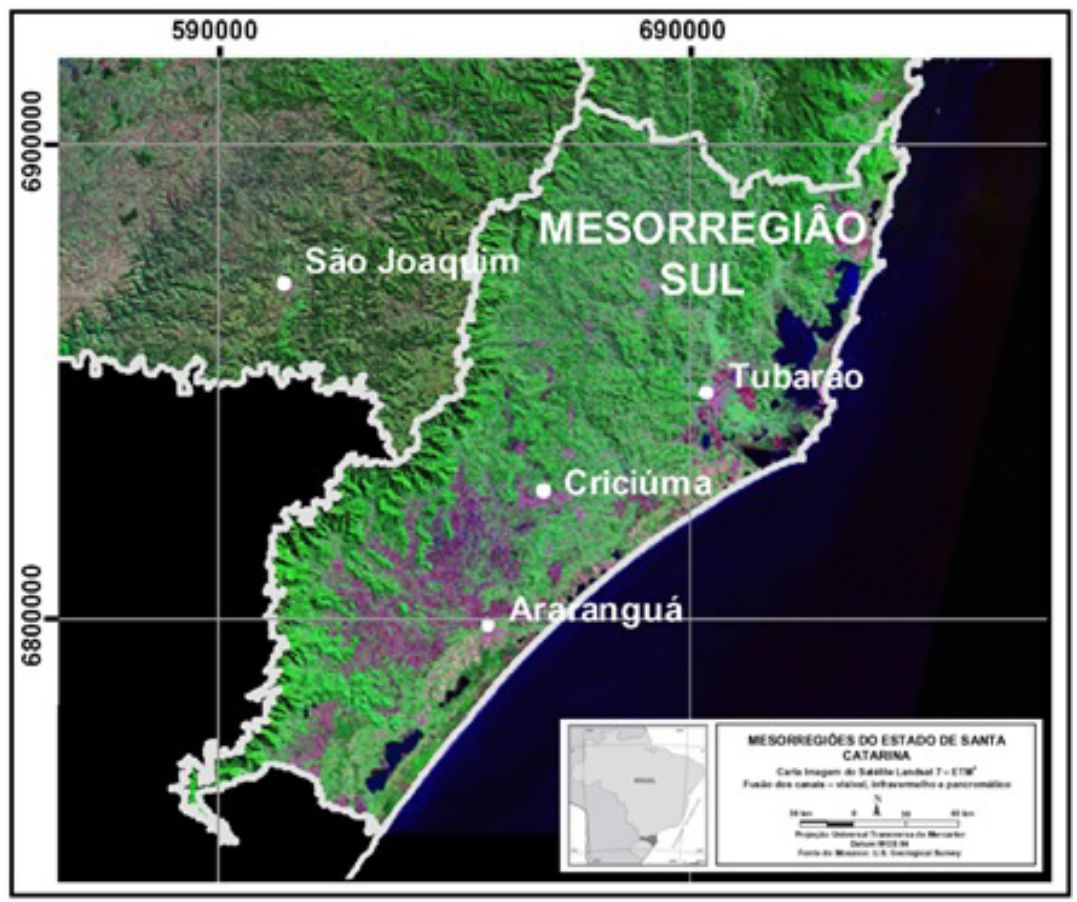

Mapa 1 - Mapa da Mesorregião Sul Catarinense

Fonte: HERRMANN, M. L. P., 2006. 
A trajetória da cidade de Tubarão ao longo dos meses de calamidade que seguiram o desastre tem foco nesta narrativa pela sua representatividade. O esforço governamental durante o período da Ditadura Civil-Militar, a preocupação com o funcionamento da Usina Termoelétrica, a ação do Exército para manter a ordem e, especialmente, o trato com os afetados são elementos que exemplificam a necessidade da reconstrução da estrutura e da ordem social para que, na opinião das classes dirigentes a cidade não deixe de existir. Assim, o presente trabalho analisa as estratégias governamentais para lidar com o desastre socioambiental, bem como, a transformação do flagelado em problema social no pós-desastre.

\section{Desastre para quem?}

O trabalho de Ted Steinberg, Acts of God: The Unnatural History of Natural Disaster in America (2006), analisa a relação dos Estados Unidos da América com eventos adversos de meados do século XVIII até o tempo presente. O historiador explica que se vale de uma perspectiva materialista, para inicialmente explorar a natureza da contingência histórica dos desastres e a cumplicidade humana. Por outro lado, também se preocupa em examinar as tentativas em restaurar a ordem depois do desastre e percebe as justificativas para preservar um particular conjunto de relações sociais. Por fim, examina as tentativas de racionalização desses eventos como algo para além do controle humano. 0 historiador estadunidense justifica sua escolha metodológica elencando três eixos de análise que considera seminais para o entendimento dos desastres e das percepções produzidas pelos sujeitos históricos: primeiro utiliza a história ambiental para compreender a interação entre seres humanos e natureza; consecutivamente se vale da história social para examinar as relações de poder entre os indivíduos; por fim, a história cultural oferece subsídios para compreender de significados e interpretações desses eventos.

Ao analisarem as enchentes de 1966 e 1967 na cidade do Rio de Janeiro, Maia e Sedrez oferecem uma série de contribuições para discussões sobre os desastres dentro da história. As historiadoras explicam que todo desastre requer algum tipo de resposta, "longe de serem simples desdobramentos das funções do Estado, as políticas públicas refletem tensões sociais especíicas, que ocupam um cenário especíico - em momentos específicos" (MAIA; SEDREZ, 2011, p. 186).

As sociedades, particularmente após um
desastre, reclamam de seus lideres e de
seus governos uma explicação para o
passado, e uma promessa para o futuro.
Ambas as respostas podem estar além
do que esses lideres querem ou podem
oferecer. As explicações cientíicas para
o desastre populacional na América
hispânica do século XVI são diferen-
tes das explicações para o desastre de
Fukushima (MAIA; SEDREZ, 2011, p. 196).

Maia e Sedrez também olham para a história social ao salientar as políticas de classe que emergem nas múltiplas narrativas dos desastres. "Nessa perspectiva, a construção da memória dos desastres, como são lembrados, e a geração das imagens representativas são fundamentais para a definição de políticas públicas" (MAIA; SEDREZ, 2011, p. 200).

Segundo o antropólogo estadunidense Anthony Oliver-Smith, os desastres têm sido fortemente estudados pelas ciências sociais nas últimas sete décadas. Durante este periodo, múltiplos conceitos e focos emergiram de variadas origens, cada um contribuindo de formas diferentes para o desenvolvimento dos estudos, entretanto existe pouco consenso na definição de desastre. Em alguns casos, a falta de consenso tem causado sérias preocupações levando em consideração a integridade do campo de pesquisa. Nessa perspectiva o autor enseja uma conceitualização do desastre e discute o desenvolvimento de uma política ecológica do desastre (OLIVER-SMITH, 1999).

Um dos pontos centrais para a conceituação do desastre está em perceber sua variabilidade e complexidade. Oliver-Smith enfatiza que a variabilidade se refere à imensa gama de fenômenos de caráter natural e tecnológico que geram "gatilhos" de desastres e produzem diferentes tipos de impactos físicos. Nesta perspectiva, "os desastres são eventos 
totalizantes" (OLIVER-SMITH, 1999, p. 20), pois neles se desenrolam todas as dimensões da formação da estrutura social. Não se pode esquecer que, a complexidade também está envolvida em uma multiplicidade de perspectivas que variam de acordo com os individuos e grupos impactados ou participantes dos eventos ou processos. Nesse ponto, enfatiza o antropólogo, é que o estudo dos desastres apesar de analisar eventos específicos no tempo e no espaço, deve empreender uma abordagem processual que inclua o acontecimento desastre e as formas de lidar com ele dentro do seu contexto.

Desastres normalmente são rotulados como eventos não rotineiros, desestabilizantes, causadores de incerteza, desordem e colapso sociocultural. Nessa lógica, são percebidos como acontecimentos que produzem a disrupção da rotina vivida e dos sistemas de compreensão (OLIVER-SMITH, 1999, p. 23).

O historiador ambiental inglês Greg Bankoff, em Comparing vulnerabilities: toward charting an historical trajectory of disasters, defende que é necessário se esquivar da comparação simplista entre vulnerabilidade e pobreza, pois a vulnerabilidade é determinada por uma combinação de fatores que inclui classe, gênero, idade, etnicidade, entre outros (BANKOFF, 2007, p. 104). Contudo, por mais que diversos fatores contribuam para estruturação da vulnerabilidade, no sul de Santa Catarina a pobreza é o maior deles. Anthony Oliver-Smith entende vulnerabilidade como

[...] as caracteristicas da pessoa ou do grupo em termos de sua capacidade de antecipar, lidar, resistir e se recuperar de um impacto de um perigo natural. Isto envolve uma combinação de fatores que determinam o grau no qual a vida de alguém e o sustento é posto em risco por um discreto ou identificado evento na natureza ou na sociedade (OLIVER-SMITH, 1999, p. 7).

Nesse sentido, a vulnerabilidade tende a expressar a multidimensionalidade dos desastres, que focaliza a atenção na totalidade das relações entre os seres humanos e o ambiente, o que, ainda segundo Oliver-Smith, deixa implícita a caracteristica fundamental da causalidade na construção dos desastres (OLIVER-SMITH, 1999. p. 9). Dar atenção aos processos que corroboram para a potencialização dos desastres usando a noção de vulnerabilidade, também permite compreender não apenas as condições de perigo do momento presente, mas, ainda, elencar como foi se produzindo ou aceitando socialmente os niveis de exposição ao risco ao longo do tempo.

\section{As águas de março}

Para além do caráter de acontecimento único, Rafael Marques insere a enchente dentro do ciclo da Fase Fria da Oscilação Decadal do Pacifico, que foi de 1946 até 1974, nesse momento se iniciava a Fase Quente, mantida até 1998 (MARQUES, 2010). Nesta conjuntura, a Temperatura da Superficie do Mar (TSM) do Oceano Pacifico tende a ficar de fria para quente, o que produz transformações climáticas até mesmo no Nordeste brasileiro (SILVA; GALVÍNCIO, 2011). Marques também explica, analisando a região de Tubarão, que os elevados totais pluviométricos registrados entre os dias 21 e 26 de março saturaram o solo, o que diminuiu drasticamente a capacidade de absorção e infiltração da água da chuva. Outro fator também considerado é a área onde a cidade de Tubarão está instalada, uma baixada aluvial, local alagadiço para onde convergem as águas que escorrem da Serra Geral (MARQUES, 2010, p. 21).

O contexto político explica muito sobre o posicionamento dos periódicos locais neste momento de Ditadura Civil-Militar (1964-1985) no Brasil, a região sul de Santa Catarina havia alcançado algum destaque em nivel nacional. $\mathrm{Na}$ necessidade de crescimento econômico, slogan do governo civil-militar que procurava de diversas formas de conter a "ameaça comunista"; o "milagre brasileiro" de 1969 até 1973 combinava um extraordinário crescimento econômico com taxas relativamente baixas de inflação (FAUSTO, 2003). O "milagre", que buscava fazer o bolo crescer para depois ser dividido, na conjuntura de 1974 ainda era uma promessa passivel de ser concretizada. $\mathrm{O}$ "milagre" multiplicou, mas não dividiu, o impacto da crescente concentração de renda foi absorvido pela expansão das 
oportunidades de emprego, "[...] em outras palavras ganhava-se menos, mas a redução era compensada pelo acesso ao trabalho de um maior número de membros de uma determinada familia" (FAUSTO, 2003, p. 485). O imperativo do crescimento fazia da região carbonífera um dos pontos de sustentação do ideário do Regime Militar no estado de Santa Catarina.

O jornalista e escritor Cesar do Canto Machado (2005), explica que aquela tinha tudo para ser uma enchente como todas as outras, "nada mais que um passageiro desconforto, pois a ocorrência de semelhante cataclismo na 'Cidade Azul', afiguravase, até ali, como pouco provável" (MACHADO, 2005, p. 20). Um ponto importante lembrado por Marques era a paulatina saturação da infiltração e absorção da água pelo solo em função da constante chuva que havia se estabelecido desde o dia 22 de março, uma sexta-feira. Foi na noite de 24 de março, uma noite de domingo, quando os moradores da cidade, despreocupados com as condições do rio e da chuva que pareciam ter perdido força e volume, estavam se preparando para dormir, a água que vinha dos morros recebeu uma descarga significativa da chuva que caia ao "pé da serra". Conforme diversas fontes, em questão de uma hora nas localidades próximas aos rios Rocinha e Bonito, formadores do rio Tubarão, a água chegava já ao teto das casas.

Ao tratar da história da cidade de Tubarão o professor e historiador Amádio Vettoretti (1992), destaca que as enchentes são marca presente na história do municipio, entretanto em 1974 os moradores da cidade haviam perdido a memória das grandes enchentes, habituandose apenas às rotineiras que castigavam mais a zona rural (VETTORETTI, 1992, p. 224). O autor. que demonstra ter um bom conhecimento sobre as dinâmicas do solo e atmosféricas, esclarece que já no dia 22 de março de 1974 algumas partes da cidade eram atingidas pelo movimento das águas, a vila Presidente Médici foi, ironicamente, a primeira. No sábado a população dos bairros mais baixos começou a se dirigir para cotas mais elevadas, "quando a cidade entrou em estado de alerta sem pânico" (VETTORETTI, 1992, p. 228).
Durante a noite de sábado para domingo (23-24 mar. 1974), apesar dos serviços de água, telefones e energia elétrica estarem funcionando normalmente, a enchente foi galgando lugares que até então não eram de costume. No amanhecer do dia 24 o prefeito decretou estado de calamidade pública; o poder público e a população se mobilizam inteiramente para lidar com a enchente que ainda parecia ser como qualquer outra.

À medida que o nivel das águas baixava na tarde de domingo, diversas pessoas começaram a voltar para suas casas. Por mais que o sentimento de irmandade daqueles acometidos pelo sofrimento seja defendido por diversos autores, houve relatos da necessidade do Exército na rua para conter os saques e roubos. A preocupação com as posses parece ser um motivo razoável para que os individuos quando percebessem a primeira diminuição das águas se dirigissem às residências.

Na noite de domingo para segunda-feira o drama da impotência alcançava tanto as casas para onde as pessoas haviam retornado quanto aquelas casas onde até então "nenhuma" água havia chegado.

Muitos dormiam e acordaram com o pé
na água. Não tinham mais saida. Houve
fugas desesperadas. A solução era subir
ao forro da casa e depois ao telhado.
Alguns na tentativa de se salvar, morre-
ram, e outros foram levados junto com
suas casas. Noite dramática. Às nove
horas, apagaram-se as luzes, os telefones
já estavam mudos. A cidade ficou sem co-
municação, isolada. Cessaram os grupos
de socorros (VETTORETTI, 1992, p. 231).

Exatamente nesse momento a narrativa os autores passa a ter aspectos em comum. As estruturas narrativas se transformam drasticamente, antes compassadas e lineares, neste momento perdem a métrica cronológica, ao que parece a ânsia em oferecer a compreensão da magnitude do evento fez com que os individuos buscassem predicados situados nos limites da compreensão humana sobre a realidade, como cataclismo, apocalipse, catástrofe, odisseia.

No municipio de Treze de Maio, emancipado de Tubarão em 1961, a ação das águas foi diferente. Um dos principais fatores está na altitude, pois o município está a 190 metros do nível do mar. 
diferente de Tubarão que tem uma altitude média de nove metros do nível do mar. Em seu livro de memórias, Fontana enfoca a sua descrição do momento da eclosão da enchente no volume de chuva, diferente dos autores que tratam da cidade de Tubarão que voltam seus olhos para os rios. A "tromba d'água" que ocorreu às 17 horas fez com que os agricultores abandonassem suas criações, passando a cuidar apenas das familias e das pessoas que por falta de mobilidade se aglutinavam nos pontos mais altos, onde normalmente eram fixadas as casas dos agricultores (FONTANA, 198-, p. 288). Fontana não relata a água entrando em sua casa, ilustra que a água passava em frente à sua residência, por isso algumas pessoas conseguiram até dormir naquela noite. Depois do café da manhã, queria ver os estragos, mas às sete horas de segundafeira outra "tromba d'água" caiu sobre a região, foi nesse momento que afirmou ver ao longe "os morros descendo" (FONTANA, 198-, p. 290). Ocorre, então, uma série de deslizamentos nas encostas da Serra Geral, mas dois oficialmente causaram mortes, no Morro do Caruru (interior de Tubarão) e na comunidade de São Gabriel (interior de Treze de Maio).

\section{Quando as águas se acalmam}

Nos escritos de Machado, em seu livro sobre a enchente de 1974, a madrugada do dia 25 parecia não ter fim. A escuridão, a falta de orientação e a impotência marcam a narrativa. Entretanto quando começa a descrição da manhã do dia seguinte, com a claridade que passava por dentre as nuvens, outros sentimentos tomam de assalto o jornalista que ficara no centro da cidade. Os enigmas carregados pela escuridão desapareceram com a chegada da luz do dia, quando "o mundo parecia ter desabado e anulado a vontade de todo o grupo" (MACHADO, 2005, p. 83).

Apesar de terem sido registrados óbitos na região de Tubarão e Praia Grande e a multidão de desabrigados cobrirem todo o sul catarinense, nenhum caso se mostrou tão desolador quanto o de Tubarão. Segundo Marques (2010), a cidade de Tubarão ficou quase completamente embaixo d'água, apenas algumas pequenas regiões com acentuada declividade, como o local onde está localizada a Igreja Matriz, ficaram ilesos.

A sensibilização pelas caracteristicas do acontecimento também é uma estratégia comum nos mais diversos escritos sobre a enchente de 1974. Os autores demonstram sentir a necessidade de oferecer ao leitor um lugar ao lado do banco de desabrigados, tal estratégia também é adotada pelos periódicos que em niveis nacional, estadual e local, que buscam aumentar seu número de leitores e oferecer uma palavra final sobre os fatos.

Durante o desastre a $3 .{ }^{a}$ Companhia de Infantaria sediada em Tubarão teve diversas funções, sendo uma delas coordenar os esforços das buscas desde o dia 22 de março quando as águas chegaram às cotas mais altas, pois os caminhões do Exército eram os poucos veículos que conseguiam passar pelos pontos que a água inicialmente dominava. Já no dia 22, o major Varella reclamava que a rádio Tubá estaria sendo sensacionalista, transmitindo pânico à população (VETORETTI, 1992, p. 83). No dia 23 a rádio foi impedida de dar notícias e ser usada por cidadãos para dar alerta, durante todo o dia até parar de funcionar na noite de 24 de março às 19 horas quando seus transmissores foram alagados. Até então a Rádio Tubá transmitira apenas música clássica.

Logo após ter registrado este acontecimento em seu livro, Vettoretti explica que na tarde de sábado, dia anterior a grande enchente, chegou de Lauro Müller, cidade a oeste de Tubarão e próxima das encostas da Serra Geral, um telegrama dizendo

[...] que saisse gritando na rua, para avisar
aos que estivessem nas partes mais
baixas, que abandonassem suas casas
imediatamente, porque um volume de
água violento, arrastando troncos, ani-
mais, casas e outros entulhos e que
provocava rugido pavoroso, chegaria
a Tubarão. Ela la telegrafista] se dirigiu
ao quartel e comunicou o comandante.
Este, sem muitas delongas, proibiu-a de
fazer qualquer apelo, porque iria apavo-
rar a população (VETORETTI, 1992, p. 83).

Para compreender tanto a magnitude do momento pós-desastre, quanto as mais 
diferentes estratégias dos individuos para sobreviver ao momento de crise, os periódicos oferecem subsidios interessantes, em razão de sua função nesse evento de sensibilização e mobilização da sociedade. Os fragmentos noticiosos foram separados majoritariamente em três categorias, definidas com base na sua circulação, pois o alcance e a definição do público alvo se relacionam diretamente com o tipo de pronunciamento gerado por cada periódico. Desta forma, como enfatiza Tânia Regina de Luca ao oferecer considerações sobre o uso de fontes impressas, a materialidade da fonte vai além das especificações técnicas, nas quais cada artefato está incluido, existe um local social de onde os pronunciamentos partem que explica muito sobre o que é escrito (LUCA, 2006).

A primeira matéria encontrada sobre a enchente que circulou em nivel nacional estava no Jornal do Brasil2 (JB) de 28 de março de 1974. quinta-feira, quatro dias depois do desastre. De forma simplória, a manchete faz referência à cheia que atingiu nove estados, com 50 mil flagelados, "a maioria das vítimas fatais está entre TubarãoSC e Torres-RS" (CHEIA EM..., 1974, p. 1). A notícia divide espaço com a iniciativa do presidente Geisel de limitar a elevação de preços de serviços em $15 \%$, aproximadamente um sexto da capa foi "dado" à medida do presidente.

A página 16 do referido periódico é inteiramente destinada a tratar das enchentes no País. Salta aos olhos a fotografia de veículos vistos do alto andando em uma estrada alagada, as pequenas ondas brancas feitas por eles oferecem contraste ao fundo escuro, pois todas as fotos do jornal são em preto e branco, onde a água está por todo o lado. A legenda localiza o leitor, "trechos inundados na BR-101, na altura de Araranguá, S. Catarina, dificultam o tráfego" (GOVERNO..., 1974. p. 16). Logo abaixo, não menos chocante, está uma foto da enchente na cidade de Sobral no interior do Ceará, na cena urbana congelada pela foto pessoas transitam a pé pela cidade onde a água chega ao limite dos joelhos, uma noção de perspectiva é utilizada para enquadrar uma rua que se estica tomada pela água até o horizonte. Em ambos os casos a narrativa inscrita na midia é a sensibilização pela magnitude do evento e os empecilhos que o desastre oferece à mobilidade.

Na página referida o Sul do Brasil está em destaque, antes do Ceará e Goiás, a escolha editorial deve ter ocorrido em função do número de mortes e desabrigados. Muito comum encontrar nos periódicos as matérias mais interessantes à linha editorial na parte superior à esquerda, justamente onde o observador pousa seus olhos, seguindo a dinâmica comum da leitura. O primeiro parágrafo explica o ocorrido, o segundo já oferece elementos para suplantar o caos instaurado no município antes de qualquer outra informação, nessa parte o Exército assume o total controle da situação e decreta toque de recolher, outras forças militares como a Força Aérea Brasileira (FAB), as Policias Militar e Civil e o Corpo de Bombeiros integram o conjunto. Posteriormente, três tópicos são trazidos para explicar melhor a situação: "medidas", "destruição" e "em Torres".

No primeiro, é descrito o rigor e imparcialidade com que as forças de recuperação trabalham na cidade, também surge o êxodo dos flagelados que segundo o jornal começam a buscar auxílio nas cidades mais próximas, estima-se que eram aproximadamente 10 mil pessoas. No tocante à "destruição", segundo tópico, o correspondente do jornal em Florianópolis explica que $20 \%$ da cidade foi destruída, e que o trabalho de recuperação já havia começado, mesmo que de forma precária pela falta de material. O Governo Federal, por meio do Ministro das Minas e Energia Shigeaki Ueki, comprometia-se no pronto atendimento às obras de recuperação. No terceiro item, o correspondente da sucursal de Porto Alegre fazia a relação das perdas na agricultura e dos desabrigados, que poderiam chegar a 1.500 pessoas, o número de mortos depois de quatro dias era de 23. Na cidade de Osório, distante 86 quilômetros de Torres, o vento sul ainda soprava e levava água até as zonas agricolas (GOVERNO..., 1974, p. 3).

\footnotetext{
2 Periódico selecionado em virtude de, em 1974 e 1983, possuir correspondentes em Santa Catarina, diferente dos periódicos O Estado de S. Paulo e Folha de S. Paulo.
} 
As notícias que se seguiram nos dias posteriores à enchente buscavam ainda oferecer a compreensão da magnitude do evento ao público nacional. Com relação ao número de mortes, no primeiro momento, quando os cômputos ainda não haviam sido oficializados, diversos dados eram noticiados, em âmbito estadual o número cogitado ficava entre 200 e 2000 (JORNAL DE SANTA CATARINA, 1974) em função da vultosa destruição, já a estimativa do Jornal do Brasil era de 500 óbitos (MORTOS..., 1974, n. 351, p. 5). A cifra oficial ficou aquém daquele imaginado, segundo Machado, o número divulgado pela Comissão Municipal de Defesa Civil de Tubarão entre desaparecidos e mortos é de aproximadamente 300 pessoas, entretanto como o mesmo autor ainda afirma, "jamais se conhecerão com certeza inteira esses amargos números" (MACHADO, 2006, p. 145). Na matéria também surge a menção sobre o prejuizo calculado de $\mathrm{Cr} \$ 1$ bilhão, que transformado em Reais com base nos reajustes da inflação seria equivalente a $\mathrm{R} \$ 2.790 .664 .750,00$.

Um assunto recorrente nos periódicos em diversos momentos era a importância do Carvão. Dos quatro ministros que passaram pela região - Euclides Quandt de Oliveira, Ministro das Comunicações; Shigeaki Ueki, Ministro das Minas e Energia; Paulo Machado, Ministro da Saúde; Alysson Paulinelli, Ministro da Agricultura (SANTA..., 1974, p. 30) - o primeiro a chegar foi o das Minas e Energia e este também foi o tema que fez a enchente continuar na vitrine nacional após o número de mortos, desabrigados e as fotos da enchente se tornarem "noticia velha". A preocupação com as motivações que levam à decisão de dar publicidade a uma notícia são, para Luca, diretamente imbricadas ao contexto social da produção da matéria (LUCA, 2006, p. 140). A preocupação contínua com a indústria carbonifera está no cerne de um projeto de desenvolvimento do pais, e para que o "Milagre Econômico" iniciado em 1969 continue multiplicando é necessária muita energia. Certamente as manchetes publicadas no Rio de Janeiro, durante a Ditadura Civil-Militar, não tinham como função sensibilizar o Governo Federal das necessidades do Sul Catarinense.
Contudo, pensar na "simples" função da informação também seria cair em um maniqueismo arbitrário, entretanto no nivel macro um dos pontos que estava em jogo era a capacidade do governo civil-militar lidar com os problemas da nação, quaisquer que fossem, sem colocar em jogo a legitimidade e capacidade do poder instituido. $O$ que pode ser averiguado pela estrutura das notícias produzidas pelo $J B$, quando, como elencado anteriormente, logo após a descrição do desastre, seguiam prontamente as medidas do Governo Federal.

A análise das matérias oferecidas nos periódicos de circulação estadual deve começar com o debate que certamente teve maior repercussão em Santa Catarina: depois da enchente ainda existia a cidade de Tubarão? Essa é uma pergunta que foi respondida de várias formas, algumas explicitas, outras implícitas. Nesse contexto a primeira matéria anexada no Caderno 1 do Arquivo Histórico Municipal de Tubarão tem o título: "Tubarão renascerá de suas próprias ruínas". Apesar de não ter data, a notícia deve ser dos primeiros dias de abril, quando o Ministro do Interior Maurício Rangel esteve na região. $O$ apelo à reconstrução da cidade chegou ao Ministro pelo governador que afirmou: "É preciso que volte a vida a correr no sangue da bravura do povo tubaronense" (TUBARÃO..., 1975, p. 9). Por mais que o sujeito visitante, o Ministro do Interior Maurício Rangel, fosse a pessoa que deveria receber o apelo do prefeito, na matéria aquele chamado à recuperação do município é o próprio povo de Tubarão.

O motivo pelo qual o governador do estado tenta conclamar os tubaronenses é, inicialmente, o êxodo que marcou o primeiro mês após o desastre. Na localidade de Caruru, a oeste da cidade no interior do municipio, onde houve um deslizamento de terra, 30 foram soterrados. Depois da enchente a localidade essencialmente agricola estava destruida, segundo a notícia, a dor do luto ainda paralisava as pessoas.

À noite, as familias se reúnem em um só lugar para orar pelos mortos. Foi numa dessas reuniões que surgiu a ideia entre alguns lavradores de se formar uma comissão para pleitear junto à Prefeitura 
de Tubarão auxilios para a recuperação das propriedades. Todavia, a iniciativa não despertou interesse na maioria, que ainda sente o efeito psicológico da tragédia (PREFEITO..., 1975, p. 8).

O acontecimento oferece alguns subsidios para compreensão da inércia das pessoas nas localidades aonde o auxilio institucional não chegava constantemente. Segundo Marques, o deslizamento no morro de Caruru em 1974 foi obra da intensa precipitação pluviométrica somada ao desmatamento nas encostas.

Apesar de, como assevera o Jornal de Santa Catarina, o número de pessoas que participam da campanha de auxilio seja incalculável (POPULARES..., 1975, p. 8), milhares de pessoas saíram de Tubarão buscando uma nova vida. $\mathrm{Na}$ capa do jornal O Estado de $1 .^{\circ}$ de abril de 1974 surge a manchete: "Prefeito teme o esvaziamento de sua cidade", já o Jornal de Santa Catarina noticiou: "Milhares já abandonaram Tubarão para sempre" (MILHARES..., 1974, p. 3). Essa última notícia traz a informação de que até o dia 30 de março de 1974, 1.120 pessoas haviam chegado de Tubarão e estavam aos cuidados da Prefeitura de Florianópolis, "em Laguna e Criciúma outras centenas de retirantes se dispõem a ficar lá e seguir em frente para recomeçar a vida" (MILHARES..., 1974, p. 3). Os primeiros retirantes do lado gaúcho também haviam chegado a Porto Alegre, muitos hospedados na casa de familiares. Milhares de flagelados também estão espalhados pelo sul catarinense, até casas de veraneio que não eram habitadas foram invadidas pelos retirantes, os que ficaram em Tubarão dependem inteiramente dos donativos. Exxodo, solidariedade e reconstrução foram palavras que circularam juntas na primeira semana depois da enchente. Os periódicos catarinenses certamente tinham um papel central na campanha de sensibilização da população não atingida para que o fluxo de donativos não cessasse.

Aqui são necessários parênteses metodológicos, que auxiliarão na leitura tanto da condição do flagelado e das suas estratégias de sobrevivência pós-desastre, quanto nas preocupações dos lideres civil-militares incumbidos de oferecer cuidados aos flagelados e zelar pela "ordem". Em Miséria da Teoria ou um Planetário de Erros (1981), o historiador britânico Edward P. Thompson, em diversos momentos, atenta para a historicidade das abstrações produzidas para a compreensão da realidade. Nesse contexto, perceber como os sujeitos definiam o que é o flagelado torna-se muito importante, ainda, deve-se ressaltar que o conceito também foi se transformando ao longo do processo de reconstrução da região. Por exemplo, na região rural, onde durante mais de dez dias a ajuda não chegara, as pessoas eram só chamadas de afetados pela enchente. Nos periódicos, o flagelado não era o indivíduo que recebia o flagelo, o sofrimento, mas, sim, aquele que poderia receber o auxilio vindo de todas as partes do País e organizado pelas classes dirigentes.

Neste trabalho também se levam em consideração as estratégias adotadas por esses sujeitos adjetivados de flagelados para em um primeiro momento garantir sua subsistência. Sobre o conceito de experiência humana, o historiador inglês, no seu embate com Louis Althusser, afirma:

Os homens e mulheres também re-
tornam como sujeitos, dentro desse
termo - não como sujeitos autônomos,
"individuos livres", mas como pessoas
que experimentam suas situações e re-
lações produtivas determinadas como
necessidades e interesses e como an-
tagonismos, e em seguida "tratam" sua
experiência com sua consciência e sua
cultura (as duas outras expressões ex-
cluídas pela pratica teórica) das mais
complexas maneiras (sim, "relativamen-
te autônomas") e em seguida (muitas
vezes, mas nem sempre, através das
estruturas de classe resultantes) agem,
por sua vez, sobre a situação determi-
nada (THOMPSON, 1981, p. 182).

Célia Regina Vendramini defende que a experiência humana, vista de uma óptica thompsoniana, apresenta-se como um elemento central "[...] para pensar a organização da vida social de forma ampla, sem perder de vista a especificidade das inúmeras experiências coletivas" (VENDRAMINI, 2012, p. 144). Diversos pronunciamentos apareciam nos jornais, como, por exemplo, o do governador de Santa Catarina, 
incentivando os habitantes a permanecerem na cidade. As demonstrações diárias de que os governos Estaduais e Federal estavam engajados na reconstrução da cidade esbarravam nos problemas sociais criados ou potencializados pela enchente, como no caso dos bairros mais atingidos serem os "populares".

O economista catalão Joan Martinez Alier discute em O Ecologismo dos Pobres (2007), a questão distributiva dos conflitos ecológicos, afirmando que embora seja amplificada a ideia de que os desastres ambientais, dada sua dimensão, repercutem na sociedade como um todo, tem diferentes reflexos, de acordo com as vulnerabilidades que cada grupo social possui.

Nesse contexto, fica claro o lugar social de frases como "ricos e pobres são iguais na catástrofe que abateu sobre Tubarão" (AS ÁGUAS..., 1974, p. 9). Na matéria que busca fazer um balanço da situação, o primeiro parágrafo é destinado ao ex-prefeito Dilney Chaves Cabral, que ao lado de sua esposa esperava pacientemente na fila de flagelados pelos gêneros alimentícios. A notícia ainda exalta o papel do Exército na distribuição de alimentos e difusão da informação.

[...] Um perfeito controle na distribuição de gêneros existe, que somente é entregue aos que foram cadastrados, mas apesar disso há pessoas de outros centros que vêm para se aproveitar da situação.

Olhar cansado, trajando uma farda cujo nome de identificação não é o seu, homem de meia idade falando calmamente, às vezes demorando alguns instantes para encontrar a palavra que possa definir a situação, assim é o Major Flávius Varela, que exerce o comando militar da comunidade, instalado no grupo escolar Hercilio Luz. Ele não demonstra esconder qualquer informação, quando instado pelos jornalistas. Ele também gravou uma mensagem ao povo, que foi transmitida às 12 horas e depois disse que a fase critica inicial de atendimento aos flagelados passou, acrescentando que a situação está "perfeitamente sob controle", embora muitos não acreditem (AS ÁGUAS..., 1974, p. 9).

A ordem construida pelo "oficial que centraliza todos os problemas de uma grande comunidade" e defendida no periódico não parece ser tão perfeita assim, a frase seguinte já contradiz essa ânsia por ordem. A notícia busca certa humanização do homem por trás do comando das ações no desastre, o Major Varella, que "não esconde informações" e é o responsável pelo fim dos pronunciamentos na Rádio Tubá durante a enchente, pronunciamentos que Vetoretti deixa implicitos que poderiam ter avisado as pessoas para seguirem às cotas mais altas antes da chegada do grande volume de água.

Sobre a necessidade da afirmação e perfeito controle da situação, deve-se frisar o embate de forças entre o Executivo Municipal e o Comando das Forças Armadas no caso da dinamitação da Barra do Camacho, na desembocadura do Rio Tubarão, pois em virtude da quantidade de sedimentos carregadas pelas águas o fluxo para o mar estava muito reduzido. A notícia do Jornal de Santa Catarina começa com a fala do prefeito de Tubarão Irmoto Feuerschutte: "A vazão rápida de um metro e meio do rio Tubarão, segunda retrasada, foi uma consequência direta da dinamitação da Barra do Camacho" (SE NÃO..., 1974, p. 3). O texto explica que o prefeito não assume a autoria do ato, que contrariava as ordens do Comando Geral, mas vê como positivo para recuperação do município.

O toque de recolher, como visto acima, tinha funções especificas de evitar os saques, que embora fossem negados pelos órgãos oficiais, ocorreram e a segurança pública, no sentido de evitar que os flagelados atacassem aqueles que não tinham sofrido com a enchente (MILHARES..., 1974. p. 3). Vale destacar que as notícias sobre saques eram raras nos jornais, apesar da menção sobre o medo ser constante. O que leva a crer no "abafamento" desse tipo de notícia por parte das autoridades para manter o nivel de ordem já estabelecido. Na área rural, os animais que haviam se abrigado nos morros à medida que eram encontrados pelas pessoas estavam sendo abatidos (MILHARES..., 1974, p. 3).

Nesse ponto a utilização do conceito de vulnerabilidade oferece elementos para a compreensão do que é considerado aceitável no campo e na cidade. Na base desse conceito está a ideia de suscetibilidade a acontecimentos de 
caráter negativo, entretanto a vulnerabilidade é um conceito dinâmico, que deve ser referencializado, pois não é uma propriedade de indivíduos ou grupos, mas construido em uma complexa teia de relações sociais e processos (HILHORST; BANKOFF, 2008). Pensando na situação local, a "permissão" social para os individuos da zona rural, menos atendidos pelo auxilio governamental que os citadinos, abaterem e distribuírem as reses a todos que - naquele momento de dificuldade - necessitam, parte de um parâmetro moral definido tanto pela ideia de necessidade, quanto pela noção de justiça.

O conceito de Economia Moral de Thompson pode ser esclarecedor para analisar a percepção dos sujeitos envolvidos no desastre em relação à noção de vulnerabilidade dos moradores do meio rural afetados pela enchente. Thompson ao enfocar os motins da fome no interior da Inglaterra do século XVIII, explica que os ataques para obtenção de alimento não ocorriam de forma espasmódica, simplesmente para suprir a fome das pessoas. Thompson esclarece que os motins eram acontecimentos gestados em um senso de justiça vinculado aos costumes do passado, pois em muitos dos casos os agitadores deixavam o pagamento pelo gênero que era levado (THOMPSON, 1998). Existe uma série de outras explicações que deveriam ser dadas sobre a Economia Moral de Thompson, entretanto esta corruptela de sua teoria já permite evidenciar que durante as situações em que a vulnerabilidade é maximizada as noções do que é justo ganham difusos contornos.

A percepção do poder público sobre os flagelados foi se transformando nos momentos pós-desastre e um caso emblemático é trazido na notícia do periódico jornal O Estado, intitulada "recadastramento pode solucionar problemas que o flagelado causa" (RECADASTRAMENTO..., 1974, p. 9). Na reportagem, a primeira distribuição de alimentos que seguia a ordem das fichas oferecidas pela prefeitura servia para suprir uma população de 88 mil habitantes e Tubarão antes da enchente possuía aproximadamente 70 mil, ou seja, alguns flagelados pegaram mais alimentos do que deveriam. A notícia ainda fala que essas pessoas foram localizadas e os gêneros apreendidos. De um momento para outro, aquelas pessoas inertes, afetadas pelo trauma da enchente, se transformaram em um novo problema social.

Para finalizar a discussão sobre o lugar social do flagelado na enchente será evidenciada uma série de pronunciamentos veiculados no vídeodocumentário gravado pela Rede Globo de Televisão 20 dias após da enchente e divulgado no programa Globo Repórter Atualidade. O documentário, disponivel na Defesa Civil de Tubarão, foi copiado em meio digital do Arquivo da Cinemateca do Museu de Arte Moderna do Rio de Janeiro.

A descrição completa da filmagem certamente propiciaria diversas discussões e tomaria muitas páginas, entretanto para o presente trabalho um ponto específico chama a atenção: a fala dos populares. Um homem negro é entrevistado na rua, sentado sob a sombra de uma laje e acompanhado de um grupo boquiaberto de crianças que olha para a câmera, fala sobre a cidade antes da enchente.

Entrevistador: Como era a cidade de Tubarão? Assim, de modo geral, antes da enchente?

Entrevistado 2: Olha rapaz não que eu queira dizer isso com orgulho, sabe. Eu no meu ramo de vida, trabalhava praticamente no meio deles ali na cidade, eu diariamente teria contato com eles. Existia aqui no nosso bairro, na Madre, Congonhas, Oficinas, por ai... O comerciante não daria bola em hipótese alguma para o operário, mesmo que ele tivesse um nivel de vida bem elevado, mas não queria nem saber, sabe? E após a enchente vê os homens conversando com Deus e todo mundo, dando bom dia, esqueceram daquele nivel deles de vida, e acho que então controlaram, e acho que então ficou todo mundo igual (GLOBO REPORTER ATUALIDADE,1974).

A fala do homem que daria prosseguimento ao assunto é cortada e depois do pronunciamento consternado de homens e mulheres, o homem volta a falar sentado em sua cadeira e rodeado de crianças. Já começa contando como as pessoas antes consideradas ricas conseguiam gêneros alimentícios sem passar pela fila, segundo ele, os empregados das pessoas chegam com bilhetes 
nos centros de distribuição e logo passavam pelos demais da fila carregando um grande "rancho". $O$ homem curvado para frente como se contasse um segredo, continua afirmando, "no início era bom, o que um ganhava todo mundo ganhava, agora a gente vê caminhão parando ali do lado e subindo rancho para cima". Quando o assunto referente aos proveitos tirados por membros da elite local começa a chegar longe demais o entrevistador faz outra pergunta.

Entrevistador: Agora... me diga o seguinte, o que mais chamou a atenção do senhor durante a enchente?

Entrevistado 2: Olha eu vou the dizer, o que mais me chamou a atenção, o que eu tive a oportunidade de perceber foi ver certas pessoas que eu jamais imaginava que eles poderiam estar na minha frente ou atrás de mim na fila pegando aquele mesmo rancho que eu tava pegando, sabe. Aquilo foi uma das partes que mais me impressionou (GLOBO REPORTER ATUALIDADE,1974).

Por mais que o entrevistador da Rede Globo quisesse dar por encerrado o assunto, o entrevistado decide voltar ao tema, ao menosprezar a magnitude das águas ou o número de mortos e desaparecidos, aquele homem negro, cercado por crianças curiosas, deixa claro que a inversão das rígidas estruturas sociais comparativamente estava além de qualquer perda material ou espetáculo da natureza. A enchente não implodiu as regras simbólicas das relações sociais, mas mostrou em um curto periodo com a desarticulação causada pelas águas que as estruturas sociais parecem mais fortes que as forças da natureza.

A explicação contida na matéria "Cálculo dos prejuizos já alcança 430 milhões" (CÁLCULO..., 1974. p. 2) o governador do estado Colombo Salles recebe estimativas da enchente de todo o seu secretariado. No segundo parágrafo, após citar todos os nomes que compunham a mesa de reuniões, a notícia explica, usando palavras do General Veiga Lima, coordenador da Defesa Civil Estadual que, entre os dias 22 e 25 de março choveram na região $2.050 \mathrm{~mm}$, nível nunca antes alcançado, sendo que nas enchentes de 1969 choveram 1.239 mm e em 1971 choveram 1.253 mm (CÁLCULO..., 1974. p. 2). Nesta conjuntura, a informação é trazida para legitimar a ideia de um evento atípico que simplesmente "aconteceu", sua explicação vai além da capacidade de compreensão dos individuos naquela época, o que avaliza a adoção de medidas puramente emergenciais para resolver o problema dos flagelados e das cheias.

\section{Considerações finais: a água vai embora}

A cidade de Tubarão, ao contrário do que muitos acreditavam, não foi riscada do mapa. Paulatinamente, ao vencer os gargalos burocráticos e ser alvo de diversas campanhas de solidariedade, foi restabelecendo os processos que faziam parte de sua dinâmica econômica. A Estrada de Ferro Teresa Cristina depois de dois meses já estava trazendo carvão bruto de Criciúma para conversão em carvão-vapor em Tubarão. Recursos do Ministério da Educação evitaram que a Fundação de Tubarão, atual Universidade do Sul Catarinense (UNISUL) parasse de funcionar, pois dos alunos que voltaram, cerca de $60 \%$ não conseguiam pagar as mensalidades. $\mathrm{Na}$ área rural a solução apontada pela Associação de Crédito e Assistência Rural de Santa Catarina (ACARESC), hoje Empresa de Pesquisa Agropecuária e Extensão rural de Santa Catarina (EPAGRI), foi distribuir sementes e insumos agrícolas - os populares agrotóxicos - aos agricultores.

De 1978 a 1982, o extinto Departamento Nacional de Obras de Saneamento (DNOS) realizou um empreendimento que transformou a dinâmica do rio com sua cidade. Com a retilinização do traçado do Rio Tubarão ao longo da zona urbana foram retirados $16.000 .000 \mathrm{~m}^{3}$ de material. Houve várias tentativas de manter a Barra do Camacho aberta, que fracassaram devido à interação dos sedimentos carregados pelas águas da Bacia Hidrográfica do Rio Tubarão com a dinâmica marinha que aglutinava os sedimentos no local. Atualmente, depois da construção de molhes e com dragagem contínua o canal permanece aberto (MARQUES, 2010, p. 27).

O "controle" do ambiente tem se mostrado funcional, desde então nenhum outro desastre 
perturbou a ordem de Tubarão como a enchente de 1974. Contudo, ainda não incidiram sobre a região índices pluviométricos como os $2.050 \mathrm{~mm}$ de 22 a 26 de março de 1974 para colocar realmente à prova os tipos de interação com o ambiente produzidos naquele contexto. O geógrafo Paulo Fernando Lago antes de qualquer explicação sobre a excepcionalidade do evento faz questão de deixar claro, de Laguna a Torres, toda região litorânea está inscrita em uma área de "bacias de inundação", onde estão subordinadas a alagações frequentes, embora nem sempre em dimensão catastrófica (LAGO, 1983). Apesar da unicidade do acontecimento e das características climáticomorfológicas o evento só se tornou uma catástrofe em função das formas de interação, tanto com o ambiente, quanto entre os seres humanos.

Por mais que se perceba o desastre como um acontecimento disruptivo, em que as estruturas da sociedade pareçam desmanteladas; os seres humanos repetem nos momentos de pretensa suspensão da ordem, as mesmas estratégias historicamente constituídas na vida social para lidar com o desastre. Apesar da suspensão das classes sociais durante a ação das águas, nos primeiros momentos do pós-desastre a segregação e as desigualdades sociais emergem junto com a lama do solo, evidencia-se, assim, ao contrário do que Bankoff (2003) preconiza, por mais que diversos fatores venham a compor a equação da vulnerabilidade ao desastre, no caso de Tubarão, a pobreza é o fator mais importante.

No caso de 1974, a calamidade foi se intensificando à medida que os pobres passaram perceber as desigualdades instituidas no processo de recuperação da cidade. A necessidade de braços para recuperação fazia das classes dirigentes, dependentes dos pobres que trabalhavam para garantir a entrega de roupas e alimentos. Um dos elementos que potencializou a equação do desastre foi a falta de informações e seu controle pelos responsáveis, como o Major Varella. Na visão dos militares a informação propagaria o caos, tal estratégia demonstra a falta de preparo para lidar com desastres socioambientais. Apenas em 2012 foi aprovada a Lei n. 12.608 de 2012, que institui a Política Nacional de Proteção e Defesa Civil. Se essa lei tivesse sido aprovada antes de 1974, a estratégia de reter ou não divulgar informações seria vista como criminal. Por fim, a cidade foi reconstruida com base nas desigualdades previamente estabelecidas.

\section{Referências}

ALIER, Joan Martinez. O Ecologismo dos Pobres. São Paulo: Contexto, 2007

AS ÁGUAS se foram, Tubarão se recupera e todos são iguais. Jornal de Santa Catarina, Florianópolis, 5 abr. 1974.

AS ÁGUAS se foram, tubarão se recupera e todos são iguais. O Estado, Florianópolis, 31 mar. 1974, p. 9

BANKOFF, Greg. Comparing vulnerabilities: toward charting an historical trajectory of disasters. Historical Social Research, Köln, v. 32, n. 3, 2007. p.103-114

BARDINI, Antonio. Conhecer para Amar. Treze de Mario: Ed. do Autor, s/d.

CÁLCULO dos prejuizos já alcança 430 milhões. Jornal de Santa Catarina, Florianópolis, 6 abr. 1974, p. 2

CHEIA EM 9 estados já faz 50 mil flagelados. Jornal do Brasil, Rio de Janeiro, 28 mar. 1974, p. 1.

CRUTZEN, Paul J.; STEFFEN, Will. How long have we been in the Anthropocene era? Climatic Change, n. 61, p. 251-257, 2003. https://doi.org/10.1023/B:CLIM.0000004708.74871.62

FAUSTO, Boris. História do Brasil. São Paulo: Editora da Universidade de São Paulo, 2003

FONTANA, Gilmar B. História de Minha Vida: memórias, imigração e outros fatos. Florianópolis: Agnus, 1998.

GLOBO REPÓRTER ATUALIDADE. Rio de Janeiro: Rede Globo. 1974. Programa de TV.

GOVERNO Geisel exibe face dinâmica no $1^{\circ}$ mês. Jornal do Brasil, Rio de Janeiro, 15 abr. 1974, p. 3.

GOVERNO recupera a zona do carvão em Santa Catarina. Jornal do Brasil, Rio de Janeiro, 8 abr. 1974, p. 4

HERRMANN, M. L. P. (org.). Levantamento dos desastres naturais ocorridos em Santa Catarina no periodo de 1980 a 2000. Florianopolis: IOESC, 2006.

HILHORST, Dorothea; BANKOFF, Greg. Introduction: mapping vulnerability. In: BANKOFF, Greg.; FRERKS, Georg.; HILHORST, Dorothea. Mapping Vulnerability: disasters, development and people. London: Earthscan, 2008. p.1-10

LAGO, Paulo. F. Calamidade: a enchente do Rio Tubarão-1974. Florianópolis: Ed. da UFSC, 1983. 
LUCA, Tania R. de. História dos, nos e por meio dos periódicos. In: LUCA, Tania R.; PINSKY, C. B. (org.). Fontes Históricas. São Paulo: Editora Contexto, 2006. p. 111-153.

MACHADO, César do C. Tubarão 1974: fatos e relatos da grande enchente. Tubarão: Ed. da UNISUL, 2005.

MAIA, Andrea; C. N. SEDREZ, Lise F. Narrativas de um Dilúvio Carioca: memória e natureza na Grande Enchente de 1966. História Oral, Rio de Janeiro, v. 2, p. 221-254, 2011.

MARQUES, Rafael. Variabilidade da precipitação na Bacia Hidrográfica do Rio Tubarão/SC de 1946 a 2006. Dissertação (Mestrado em Geografia) - Universidade Federal de Santa Catarina, Centro de Filosofia e Ciências Humanas, Programa de Pós-graduação em Geografia, Florianópolis. 2010. 206 p.

MILHARES já abandonaram Tubarão para sempre. Jornal de Santa Catarina, Florianópolis, 1 abr. 1974, p. 3

OBSTRUÇÃO de ferrovia ameaça siderúrgica no Sul. Jornal do Brasil, Rio de Janeiro, 2 abr. 1974, p. 7.

OLIVER-SMIYH, Anthony. "What is a Disaster": Anthropological perspectives on a persistent question. In: OLIVER-SMITH, Anthony; HOFFMAN, Susanna. M. (org.). The Angry Earth: Disaster in Anthropological Perspective. London: Routledge, 1999. p.15-36. https://doi.org/10.4324/9780203821190

POPULARES buscam os 10 corpos dos 30 que ficaram soterrados em Caruru. O Estado, Florianópolis, 2 abr. 1974, p. 8.

PREFEITO teme o esvaziamento de sua cidade. 0 Estado, Florianópolis, 02 abr. 1974, p. 8.

Rangel garante apoio federal para Santa Catarina. Jornal do Brasil, Rio de Janeiro, 6 abr. 1974, p. 13

RECADASTRAMENTO pode solucionar problemas que o flagelado causa. O Estado, Florianópolis, 10 abr. 1974, p. 9.

SANTA Catarina recebe visita de 3 ministros. Jornal do Brasil, Rio de Janeiro, 31 mar. 1974, p. 30.

SE NÃO dinamitassem a barragem, morreriam muitos mais. Jornal de Santa Catarina, Florianópolis, 5 abr. 1974, p. 3.

SILVA, Djane F. da; GALVÍNCIO, Josiclêda D. Estudo da Influência da Oscilação Decadal do Pacífico no Nordeste do Brasil. Revista Brasileira de Geografia Fisica, v. 4, p. 665-676, 2011. Disponivel em: http:// www.ufpe.br/rbgfe/index.php/revista/article/viewFile/142/198. Acesso em: 15 abr. 2013. https://doi. org/10.26848/rbgf.v4i4.232677

STEINBERG, Ted. Acts of God: The Unnatural History of Natural Disaster in America. Oxford: Oxford University Press, 2006

THOMPSON, Edward P. Costumes em Comum: estudos sobre a cultura popular tradicional. São Paulo: Cia das Letras, 1998.

THOMPSON, Edward P. Miséria da Teoria ou um Planetário de Erros. Rio de Janeiro: Zahar, 1981.
TUBARÃO renascerá de suas próprias ruinas. O Estado, Florianópolis, 28 mar. 1974, p. 9.

VENDRAMINI, Sandra R. Experiência e coletividade em E. P. Thompson. In: DUARTE, Adriano L.; MÜLLER, Ricardo. G. E. P. Thompson: política e paixão. Chapecó: Argos, 2012.

VETTORETTI, Amadio. História de Tubarão: das origens ao século XX. Tubarão: Prefeitura Municipal de Tubarão, 1992.

\section{Alfredo Ricardo Silva Lopes}

Doutor em História pela Universidade Federal de Santa Catarina (UFSC, Florianópolis, SC, Brasil). Pós-doutorado em Letras, pela Universidade Federal do Mato Grosso do Sul (UFMS). Professor Adjunto no Curso de História do Campus do Pantanal da Universidade Federal do Mato Grosso do Sul (UFMS).

\section{Endereço para correspondência}

Alfredo Ricardo Silva Lopes

Universidade Federal do Mato Grosso do Sul

Avenida Rio Branco, 1.270

Bairro Universitário, 79304-902

Corumbá, MS, Brasil 